\title{
Emmetropisation, squint, and reduced visual acuity after treatment
}

\author{
R M Ingram, P E Arnold, S Dally, J Lucas
}

\begin{abstract}
In a sample of children used to assess the value of optical correction of hypermetropia from the age of 6 months the refraction of the most hypermetropic meridian frequently became less than $3.5 \mathrm{D}$ as the children grew. When this occurred, the incidence of squint was significantly less $(p<0.001)$ and the last known acuity after treatment was significantly better $(p<0.001)$ than when it did not. This process of emmetropisation appears to have been impeded by the consistent wearing of hypermetropic spectacle correction from the age of 6 months.
\end{abstract}

Fabian $^{1}$ first noticed that, if refractions were recorded as spherical equivalents, the wide range found in infants became narrower as the children grew. He called the process 'emmetropisation.' An example of this is the reduction of astigmatism that occurs after the age of 6 months. ${ }^{2-7}$ The basic spherical refraction may not change significantly, ${ }^{37}$ but our study of changes in the refraction of individual meridia between the ages of 1 and $31 / 2$ years ${ }^{3}$ confirmed Fabian's observations if the initial level of hypermetropia was $+2 \cdot 50 \mathrm{D}$ or less. However, if the level of hypermetropia in a given meridian was $>2.50 \mathrm{D}$ at 1 year, there was an almost even chance that the level of hypermetropia increased, not decreased.

When we assessed the results of our trial of optical correction of hypermetropia from the age of 1 year $^{8}$ we suspected two things: (1) the children who squinted were those who remained hypermetropic, but if the initial level of hypermetropia in a child decreased the prognosis for squint and amblyopia was better; (2) children drawn for treatment with spectacles appeared to remain hypermetropic. We could not prove either of these suspicions, principally because we did not know what was a 'normal' amount of hypermetropia at a given age. We therefore decided to look again for an association between reduction of hypermetropia and the visual outcome in children included in our recent trial of treating hypermetropia from the age of 6 months. ${ }^{9}$ In order to do this we arbitrarily chose a level of hypermetropia below which we deemed that emmetropisation occurred. Since the criterion for entry into this trial was the level of hypermetropia in the most hypermetropic meridian of a pair of eyes, we continued to use this method of recording hypermetropia. We also report observations on the possible effect of wearing spectacles on the process of emmetropisation

Patients and methods

The sample of children is the one reported in our trial of treating abnormal hypermetropia with spectacles from the age of 6 months $^{9}$ in an attempt to prevent squint and amblyopia. Details of the protocol used to conduct that trial were reported in that paper. ${ }^{9}$ Three hundred and seventy two infants, aged 6 months, with $+4 \cdot 00$ or more dioptres hypermetropia in one or more meridia of either eye were randomly allocated treatment with spectacles or no treatment, and followed up as effectively as possible. If a child in either group developed a squint, or was found (usually at age $31 / 2$ years) to have reduced visual acuity, he/she was treated conventionally with spectacles, occlusion, or operation as appropriate. The presence of squint was diagnosed with the cover test. Visual acuity was recorded only with Linear Sheridan-Gardiner or Snellen tests. All the refractions were done by the same person (RMI) after cycloplegia with cyclopentolate $1 \%$. The refraction reported is the amount of hypermetropia in the most hypermetropic meridian after $+1.75 \mathrm{D}$ has been subtracted from the retinoscopy findings of all meridia of a pair of eyes. Information abut the refractions, presence of squint, and the last known visual acuity after any additional treatment had been given is now available for 287 of the children.

The first purpose of this paper is to relate the reduction of hypermetropia that occurred after the age of 6 months to the presence of squint and the last known corrected visual acuity in the case of 143 children who were drawn for no treatment. Secondly, the changes of refraction of these children have been compared with those of the 144 children who were drawn to wear spectacles.

\section{Results}

Since there are no published guidelines on how one could judge whether emmetropisation had occurred, or indeed by what age it should have occurred, we have had to set limits arbitrarily. The age of $31 / 2$ years was chosen as the time by which emmetropisation should have taken place if it was going to do so, but we could not stick rigidly to that time because 23 children drawn for no treatment were diagnosed as having convergent squint before $31 / 2$ years, and were treated with spectacles. Eighteen of these 23 children had +3.50 or more dioptres meridional hypermetropia when the squint was diagnosed, and there is a suggestion (see later in this paper) that treatment could have encouraged them to remain hypermetropic after glasses had been prescribed. Therefore, on the assumption that failure to reduce infantile hypermetropia soon enough might be a cause of squint, we decided to take the refraction at the age of $31 / 2$ years, or at the time a squint was diagnosed if that was before the child reached $31 / 2$ years in order to judge whether 
emmetropisation had occurred. Secondly, since we do not yet know what level of hypermetropia, in the most hypermetropic meridian of a pair of eyes, is 'normal' for a given age, we have arbitrarily chosen a figure of $+3 \cdot 50 \mathrm{D}$ in any one meridian as the dividing line. Astigmatism and anisometropia have been ignored.

EMMETROPISATION AND INCIDENCE OF SQUINT Complete information is available on 143 children who were initially drawn for no treatment. From the figures shown in Table 1 it is clear that those children whose hypermetropia remained at or above $+3.50 \mathrm{D}$ had a higher incidence of squint. This difference is statistically significant $(p<0 \cdot 001)$.

\section{EMMETROPISATION AND LAST KNOWN VISUAL ACUITY}

We have not attempted to relate emmetropisation to whether a child did or did not have amblyopia, because it is difficult to define 'amblyopia' in terms of any given visual acuity. In addition some of these children had occlusion before their visual acuity could be accurately assessed. Therefore we record the last known acuity of the worse-seeing eye after all treatment, including occlusion, had been given. This is worse in the case of those children in whom emmetropisation was considered not to have occurred. The results are summarised in Table 2 , and the difference is significant whichever way the figures are arranged for statistical analysis. As they stand, $\mathrm{p}<0.001$, but, if a dividing line is drawn between those whose last known acuity was $6 / 9$ or better and those with $6 / 12$ or worse, $\chi^{2}=26.34, p<0.001$. If a dividing line is drawn between $6 / 12$ or better and $6 / 18$ or worse, $\chi^{2}=$ $11.97, \mathrm{p}<0.001$. Similarly, if a line is drawn between $6 / 18$ or better and $6 / 24$ or worse, $\chi^{2}=9.45, \mathrm{p}<0.01$.

\section{POSSIBLE EFFECT ON EMMETROPISATION OF} WEARING HYPERMETROPIC SPECTACLES FROM THE AGE OF 6 MONTHS

Similar information was available in the case of 144 children who were randomly allocated treatment with spectacles from the age of 6 months, and this permits observations on the question of whether treatment with spectacles caused these infants to remain hypermetropic. A valid com-

Table 1 Emmetropisation and squint

\begin{tabular}{lll}
\hline & No squint & Squint \\
\hline Emmetropisation had not occurred & 16 & 29 \\
Emmetropisation had occurred & 88 & 10 \\
\hline
\end{tabular}

$\chi^{2}=43 \cdot 05, \mathrm{df}=1, \mathrm{p}<0 \cdot 001$.

Table 2 Emmetropisation and the last known visual acuity

\begin{tabular}{lllll}
\hline & $6 / 6$ and $6 / 9$ & $6 / 12$ & $6 / 18$ & $6 / 24$ or worse \\
\hline Emmetropisation had & 23 & 9 & 5 & 8 \\
not occurred & & 3 & 4 & 2 \\
$\begin{array}{l}\text { Emmetropisation had } \\
\text { occurred by } 31 / 2\end{array}$ & 89 & & & \\
\hline$\chi^{2}=30 \cdot 05, \mathrm{df}=3, \mathrm{p}<0 \cdot 001$. & & &
\end{tabular}

Table 3 Emmetropisation and the prescription of spectacles from age 6 months

\begin{tabular}{lll}
\hline & $\begin{array}{l}\text { Children allocated } \\
\text { spectacles }\end{array}$ & $\begin{array}{l}\text { No treatment } \\
\text { allocated }\end{array}$ \\
\hline $\begin{array}{l}\text { Emmetropisation had } \\
\text { not occurred }\end{array}$ & 60 & 45 \\
$\begin{array}{l}\text { Emmetropisation had } \\
\text { occurred }\end{array}$ & 84 & 98 \\
\hline
\end{tabular}

$\chi^{2}=2 \cdot 79, \mathrm{df}=1, \mathrm{p}>0.05$.

parison of the effect of prescribing spectacles on emmetropisation can be made when the fate of all those drawn for treatment is compared with those drawn for no treatment. When this is done (Table 3), there is a suggestion that the prescription of spectacles might have impeded emmetropisation, but the difference is not statistically significant ( $p>0.05)$. A proportion of the children allocated spectacles did not wear them. At each follow-up attendance an assessment of compliance with treatment was attempted. ${ }^{9}$ This group can therefore be subdivided into those who seemed to be wearing their glasses consistently $(\mathrm{T}+)$, and those who were obviously not doing so $(\mathrm{T} \pm)$. If the sub-group who consistently wore their glasses $(\mathrm{T}+)$ are compared with those who wore their glasses some of the time or not at all $(\mathrm{T} \pm)$, and with those drawn for no treatment, the numbers of children who reduced their hypermetropia or did not do so are as follows (Table 4). The sub-group $\mathrm{T}+$ were significantly less likely to have reduced their meridional hypermetropia to less than $+3 \cdot 50 \mathrm{D}$ than either the sub-group who wore their glasses inconsistently $(T \pm)\left(\chi^{2}=9.96, p<0.01\right)$, or those originally drawn for no treatment $\left(\chi^{2}=10.57, \mathrm{p}<0.01\right)$.

Most of those children whose meridional hypermetropia became less than $+3.50 \mathrm{D}$ had achieved this by the age of 1 year. $82 \%$ of those drawn for no treatment, and who were considered to have corrected their hypermetropia, had done so by 1 year. The corresponding figure for those drawn for treatment but whose compliance was judged to be poor $(T \pm)$ was $63 \%$, and for those who consistently wore their glasses $(\mathrm{T}+)$ was $47 \%$. Thus delay in emmetropisation was apparent by the age of 1 year.

Table 4 Emmetropisation and the consistent wearing of spectacles

\begin{tabular}{llll}
\hline & $\begin{array}{l}\text { Subgroup } \\
T+\end{array}$ & $\begin{array}{l}\text { Subgroup } \\
T \pm\end{array}$ & $\begin{array}{l}\text { Children drawn } \\
\text { for no treatment }\end{array}$ \\
\hline $\begin{array}{l}\text { Emmetropisation had } \\
\text { not occurred }\end{array}$ & 39 & 21 & 45 \\
$\begin{array}{l}\text { Emmetropisation had } \\
\text { occurred }\end{array}$ & 31 & 53 & 98 \\
\hline
\end{tabular}

Table 5 Initial meridional hypermetropia of children in each of the three subgroups

\begin{tabular}{llll}
\hline $\begin{array}{l}\text { Meridional } \\
\text { hypermetropia } \\
\text { at 6 months }\end{array}$ & $\begin{array}{l}\text { Number of } \\
\text { children } \\
\text { in subgroup } \\
(T+)\end{array}$ & $\begin{array}{l}\text { Number of } \\
\text { children } \\
\text { in subgroup } \\
(T \pm)\end{array}$ & $\begin{array}{l}\text { Number of } \\
\text { children } \\
\text { drawn for } \\
\text { no treatment }\end{array}$ \\
\hline+4.00 & 27 & 33 & 74 \\
+4.50 & 13 & 19 & 28 \\
+5.00 & 14 & 8 & 20 \\
+5.50 & 8 & 7 & 7 \\
+6.00 & 5 & 6 & 9 \\
+6.50 & 0 & 1 & 3 \\
+7.00 or more & 3 & 0 & 2 \\
\hline
\end{tabular}


One might reasonably guess that those infants who were initially most hypermetropic would be the ones least likely to correct their hypermetropia. Such children might also be more likely to derive benefit from wearing glasses, wear them consistently, and therefore fall into the $\mathrm{T}+$ subgroup. If this had happened, it could have biased the findings towards our observation that consistent wearing of spectacles appears to have impeded emmetropisation. This is unlikely to have been the case, however, because there was not an obvious preponderance of infants with the higher levels of meridional hypermetropia among the $\mathrm{T}+$ subgroup (Table 5).

\section{Discussion}

The classical view that all infants are hypermetropic $^{10}$ and that those who remain hypermetropic are particularly likely to present with accommodative esotropia has never been demonstrated. All infants are not 'abnormally' hypermetropic. ${ }^{11}$ Only about $10 \%$ of those that we screened at 6 months were sufficiently longsighted to be included in our trial of preventive treatment. However, if the criteria, which we have chosen arbitrarily, to decide whether emmetropisation had or had not occurred are accepted, there is confirmation that in the case of 'abnormally' hypermetropic infants failure to reduce their hypermetropia is associated with subsequent identification of squint (Table 1 , $p<0.001)$. We have independently made the same observations as Aurell and Norrsell. ${ }^{12}$ Our sample of children, however, was not restricted to those with a family history of squint/ amblyopia.

We think that emmetropisation was most likely to have occurred before the age of 1 year, though the process did continue after then. We found that those children whose meridional hypermetropia was not reduced to less than $+3.50 \mathrm{D}$ were significantly more likely (Table 2 , $\mathrm{p}<0.001$ ) to end up with worse visual acuity than those whose hypermetropia was reduced to less than +3.50 D. The association between emmetropisation on the one hand and a lower incidence of squint and better visual acuity on the other hand was statistically more significant than any improvement that could be shown following the prescription and wearing of glasses in the same sample of children. ${ }^{9}$ The promotion of emmetropisation, if that were possible, might be preferable to enthusiastic prescription of spectacles as a method of preventing squint and improving visual acuity. Basic information about emmetropisation in animals is being reported, but we need to know what factors could affect it in man.

Our observations about the effect of spectacles on emmetropisation in this sample of children may give a clue to this. The prescription of glasses did not significantly impede emmetropisation (Table 3), but, when those children drawn to wear spectacles were separated into two subgroups, those who were judged to have consistently worn their glasses $(T+)$ were significantly less likely to have reduced their hypermetropia than either those who probably or certainly did not wear glasses consistently $(T \pm$ ) (Table 4 , $\mathrm{p}<0.01)$ or those who were randomly allocated no treatment (Table 4, p<0.01). Although judgment on whether glasses had been worn consistently was made before these figures were worked out, those regarded as having consistently worn glasses might be considered to be a self-selected group. Nevertheless, these findings support Lyle's speculation ${ }^{10}$ that spectacle correction of hypermetropia might impede emmetropisation. They also confirm the observations of Dobson et al, ${ }^{13}$ who have reported that 10 infants, prescribed spectacles because they had convergent squint, showed a significantly smaller decrease in hypermetropia than a group of 30 non-strabismic infants with equivalent hypermetropia who were not prescribed spectacles.

So far as we are aware there are only two other reports of the opposite of emmetropisation in children - that is, increasing hypermetropia at some time between birth and the age of 7 years. Both studies were conducted on patients, not random samples of the population. Over twothirds of Brown's subjects ${ }^{14}$ had squint, and most of those probably wore hypermetropic spectacles. Many of Slataper's subjects were probably treated for squint also. ${ }^{15}$ Some children being treated for accommodative esotropia do become more hypermetropic, ${ }^{16}$ and this change could be influenced by the wearing of hypermetropic spectacles. The mechanism of such an influence is problematical but could include a reduction in the need for accommodation, and accommodation in its turn might be involved in the reduction of hypermetropia. As a corollary to this, some believe that excess accommodation is one factor contributing to the increase in myopia at or after puberty.

We thank Mrs $\mathrm{L}$ Neale for many hours of secretarial and administrative work.

1 Fabian G. Augenarztliche Reihenuntersuchung von 1200 kindern im 2 Lebensjahr. Acta Ophthalmol (Kbh) 1966; 44 473-9.

2 Gwiazda J, Scheiman M, Mohindra I, Held R. Astigmatism in children. Changes in axis and amount from birth to 6 years. Invest Ophthalmol Vis Sci 1984; 25: 88-92.

3 Ingram RM, Barr A. Changes in refraction between the ages of I and $31 / 2$ years. Br $\mathcal{F}$ Ophthalmol $1979 ; 63: 339-42$.

4 Atkinson J, Braddick OJ, French J. Infant astigmatism: its disappearance with age. Vision Res 1980; 20: 891-3.

5 Fulton AB, Dobson V, Salem D, Mar C, Petersen RA Hansen RM. Cycloplegic refraction in infants and young children. Am f Ophthalmol 1980; 90: 239-47.

6 Howland HC, Sayles N. Photokeratometric and photorefractive measurements of astigmatism in infants and young children. Vision Res 1985; 25: 73-81.

7 Abrahammson M, Fabian G, Sjostrand J. Changes in astigmatism between the ages of 1 and 4 years: a longitudina study. Br $\mathcal{F}$ Ophthalmol 1988; 72: 145-9.

8 Ingram RM, Walker C, Wilson JM, Arnold PE, Lucas J, Dally S. A first attempt to prevent amblyopia and squint by spectacle correction of abnormal refractions from age 1 year. Brf Ophthalmol 1985; 69: 851-3.

9 Ingram RM, Arnold PE, Dally S, Lucas J. Results of a randomised trial of treating abnormal hypermetropia from randomised trial of treating abnormal hypermetropia

10 Lyle TK. Worth and Chavasse's squint. 8th ed. London: Baillière, Tindall, and Cox, 1950: 22-3, 134, 254.

11 Ruskell GL. Some aspects of vision in infants. Br Orthopt $\mathcal{F}$ 1967; 24: 25-32.

12 Aurell E, Norrsell K. A longitudinal study of children with a family history of strabismus: factors determining the incidence of strabismus. Brf Ophthalmol 1990; 74: 589-94.

13 Dobson V, Sebris SL, Carlson MR. Do glasses preven emmetropisation in strabismic infants? Invest Ophthalmol Vis Sci 1986; 27 (ARVO suppl): 2.

14 Brown EVL. Net average yearly changes in refraction of atropinised eyes from birth to beyond middle life. Arch Ophthalmol 1938; 19: 719-34.

15 Slataper FJ. Age norms of refraction and vision. Arch Ophthalmol 1950; 43: 466-79.

16 Parks MM. Management of acquired esotropia. Br $7 \mathrm{Oph}$ thalmol 1974; 58: 240-7. 